\title{
A STUDY TO EVALUATE SOCIO-CULTURAL IMPACT OF INTERNET ON THE
} POST GRADUATE STUDENTS

\section{Dr. A. J. Bharvad}

\&

\section{Ms. Meenu Gupta}

\begin{abstract}
:
This Paper deals with the study of the Extent of Internet Use and its Socio Cultural Impact on the Post Graduate Students of the Gujarat State. To know the Socio Cultural Impact of Internet, standardized opinionnaire (offline as well online) was used. The main objectives of the study were to evaluate the extent of Internet Utilization and to know the effect of independent variables like Gender, Academic Stream and frequency of Internet Access of Internet on the P.G. students who were using Internet since last two years or more than two years. Analysis of Variance was done to know the effect of independent variables and their interaction effects. The population of the study consisted of the P.G. students and the samples were taken from nine Universities of Gujarat (Zone wise). The finding of the study shows significant interactive influence between Gender, Academic Stream and Frequency of Internet Access on the Socio-Cultural impact of internet.
\end{abstract}

\section{Introduction:}

The Internet is a global computer network sometimes simply called "the net". It provide a platform where people across the world can communicate, exchange messages, share knowledge and interact with each other regardless of the distance \& time. People across the world can stay in touch and feel closer and more connected. Internet has brought people from different cultures together in a 'Global Village.' The intercultural dialogue are happening and different cultures encounter each other through use of social media such as Facebook, twitter \& you tube etc. in this Global Village.

\section{Socio-cultural impact of the Internet:}

- When we speak of social change, we might assert that there is some change in social behaviour and in social structure.

- Social behaviour refers to the customs, manners, food habits and speech habits i.e. the way we live and interact with others in day to day life. 
- Whereas the changes in social structure refers to family structure, marriage structure, caste structure, labour conditions, institutional structure etc.

* Dr A J Bharvad, Professor, Department of Education, Gujarat University, Ahmedabad

** Meenu Gupta, Researcher, Pursuing Ph.D., Department of Education, Gujarat University

- Our values, ideas, moral, traditions, belief, habits, attitude, manners, dressing style, way of celebrating festivals and way of worship are the products of our culture.

The researcher wanted to know the effect of the wide spread use of internet on behaviour, habits, tradition and beliefs among the students.

\section{Statement of the Problem}

A Study to Evaluate Socio Cultural Impact of Internet on the Post Graduate Students.

\section{Variables:}

1. Independent variables 1.Gender: (i) Male (ii) Female 2.Academic Stream: (i) Science Stream (ii) others Stream 3.Frequency of Internet Use: (i) Normal Users (ii) Excessive Users

2. Dependent variable: Socio Cultural Impact on the P. G. Students

\section{Objectives of the study:}

$>$ To study the extent of utilization of the internet on the University PG students of Gujarat.

$>$ To study the effect of independent variables on the social-culture impact of internet use on the PG students of Gujarat.

To study the effect of interaction between and among independent variables on the social-culture impact of internet use on the PG students of Gujarat.

\section{The Hypothesis (Ho) -}

The following were the hypotheses of the study

$H o_{1}$ - There will be no significant influence of Gender on social-cultural impact of the internet on the PG students of Gujarat State.

$\mathrm{Ho}_{2}$ - There will be no significant influence of Academic Stream on social-cultural impact of internet on the PG students of Gujarat State.

$\mathrm{Ho}_{3}$ - There will be no significant influence of frequency of internet access on socialcultural impact of internet on the PG students of Gujarat State.

$\mathrm{Ho}_{4}$ - There will be no significant interactive influence between gender and academic stream on social-cultural impact of internet on the PG students of Gujarat State. 
Towards Excellence: An Indexed, Refereed \& Peer Reviewed Journal of Higher Education / Mr. A.J Bharvad \& Ms. Meenu Gupta / Page 1-9

$\mathrm{Ho}_{5}$ - There will be no significant interactive influence between gender and frequency of internet access on social-cultural impact of internet on the PG students of Gujarat State.

$\mathrm{Ho}_{6}$ - There will be no significant interactive influence between academic stream \& frequency of internet access on social-cultural impact of internet on the PG students of Gujarat State.

$\mathrm{Ho}_{7}$ - There will be no significant interactive influence among gender, academic stream \& frequency of internet access on social-cultural impact of internet on the PG students of Gujarat State.

\section{LIMITATIONS OF THE STUDY}

1. The students of other than Gujarat state of India were not included in the present study.

2. Other than PG students were not included in the present study.

\section{METHOD OF THE STUDY}

Survey method was adopted to know the extent of internet use and its socio-cultural impact on PG University students of Gujarat State.

\section{POPULATION AND SAMPLE OF THE STUDY}

PG students of State universities of Gujarat state were the population. The Gujarat State was divided in four zones and i.e. Central (Gujarat University, GTU and Anand University), Saurashtra (Rajkot, Bhavnagar and Bhuj), South (Surat and Vadodara) and North (Patan). The students were chosen based on proportional stratified random sampling technique to ensure that post graduate students from all zones in Gujarat State gets adequately represented in the sample. Out of total 821 samples, 25 number of respondents under the three variables were selected randomly from among total numbers of respondents of same category according to $2 * 2 * 2$ factorial design as shown below:

Table-1 Sample of the Study

\begin{tabular}{|c|c|c|c|c|c|c|c|c|c|}
\hline Internet use & \multicolumn{4}{|c|}{ Normal Users $\left(A_{1}\right)$} & \multicolumn{4}{|c|}{ Excessive Users $\left(A_{2}\right)$} & \multirow{3}{*}{$\begin{array}{l}\overline{\widetilde{0}} \\
\stackrel{0}{\circ}\end{array}$} \\
\hline Gender & \multicolumn{2}{|c|}{ Male $\left(\mathbf{B}_{1}\right)$} & \multicolumn{2}{|c|}{ Female $\left(\mathbf{B}_{2}\right)$} & \multicolumn{2}{|c|}{ Male $\left(\mathbf{B}_{1}\right)$} & \multicolumn{2}{|c|}{ Female $\left(\mathbf{B}_{2}\right)$} & \\
\hline Stream & $\operatorname{Sci}\left(\mathrm{C}_{1}\right)$ & $\operatorname{Others}\left(\mathbf{C}_{2}\right)$ & Sci $\left(\mathbf{C}_{1}\right)$ & Others $\left(C_{2}\right)$ & $\operatorname{Sci}\left(\mathbf{C}_{1}\right)$ & $\operatorname{Others}\left(\mathrm{C}_{2}\right)$ & Sci $\left(\mathbf{C}_{1}\right)$ & Others $\left(C_{2}\right)$ & \\
\hline $\mathbf{N}$ & 25 & 25 & 25 & 25 & 25 & 25 & 25 & 25 & 200 \\
\hline Groups & $A_{1} B_{1} C_{1}$ & $A_{1} B_{1} C_{2}$ & $\mathrm{~A}_{1} \mathrm{~B}_{2} \mathrm{C}_{1}$ & $A_{1} B_{2} C_{2}$ & $\mathrm{~A}_{2} \mathrm{~B}_{1} \mathrm{C}_{1}$ & $A_{2} B_{1} C_{2}$ & $\mathrm{~A}_{2} \mathrm{~B}_{2} \mathrm{C}_{1}$ & $\mathrm{~A}_{2} \mathrm{~B}_{2} \mathrm{C}_{2}$ & \\
\hline
\end{tabular}


Towards Excellence: An Indexed, Refereed \& Peer Reviewed Journal of Higher Education / Mr. A.J Bharvad \& Ms. Meenu Gupta / Page 1-9

\section{TOOLS OF THE STUDY}

In the present study, the following tools were used to collect data:

Tool 1: Self-prepared tool for testing the extent of internet utilisation. The Internet extent scale was a self-reporting five point scale. For deciding the groups, Median was calculated on the scores of the Internet Extent scale. The Median was 25, so the students who got below 25 scores were considered as a Normal Users and the students who got 25 and above were considered as Excessive Users.

Tool 2: Self-prepared tool standardized by the investigator before administrating to the students to find out the socio-cultural impact of the Internet. It was a five point scale containing 41 statements out of which 20 statements were positive and 21 statements were negative.

The investigator also prepared a google form with a tiny web-link (www.tinyurl.com/phdform). The web link was circulated in the whatsapp groups and institute emails of the respective PG departments.

\section{Data Collection and Analysis}

The data gathered through standardised tool was analysed and interpreted. The raw scores were recorded in $2 \times 2 \times 2$ factorial design. First of all, calculation was done for the Bartlet's test of homogeneity. The calculated value of chi-square2 7.4198 was less than table value 41.64 for df 23 at 0.01 level of significance. This shows that the homogeneity of variance was maintained.

\section{Table- 2 Summary of ANOVA}

\begin{tabular}{|l|r|r|r|r|}
\hline \multicolumn{1}{|c|}{ Source of Variation } & \multicolumn{1}{c|}{ df } & $\begin{array}{c}\text { Sum of } \\
\text { Squares }\end{array}$ & $\begin{array}{c}\text { Mean } \\
\text { Square }\end{array}$ & \multicolumn{1}{c|}{ F } \\
\hline Gender & 1 & 34.56 & 34.56 & 0.42 \\
\hline Stream & 1 & 66.67 & 66.67 & 0.81 \\
\hline Int. Use & 1 & 240.67 & 240.67 & 2.94 \\
\hline Gender X Stream & 1 & 74.08 & 74.08 & 0.90 \\
\hline Gender X Int. Use & 1 & 48.16 & 48.16 & 0.59 \\
\hline Stream X Int. Use & 1 & 285.65 & 285.65 & 3.49 \\
\hline Gender X Stream X Int. Use & 1 & 384.01 & 384.01 & 4.69 \\
\hline
\end{tabular}

$\mathrm{F}(1,192)=6.76$ at 0.01 level of Significance

$\mathrm{F}(1,192)=3.89$ at 0.05 level of Significance

\section{Study of Null Hypotheses}

\section{Study-1 Influence of Gender on social-cultural impact}

$\mathrm{F}$ ratio 0.42 of Gender was compared with $\mathrm{F}$ table value and it was found that observed $\mathrm{F}$ value is less than 6.76 at 0.01 level of significance. Also $t_{\text {cal }}$ is 0.64 , which is less than 1.96 
Towards Excellence: An Indexed, Refereed \& Peer Reviewed Journal of Higher Education / Mr. A.J Bharvad \& Ms. Meenu Gupta / Page 1-9

( $\mathrm{t}_{\mathrm{tab}}$ at 0.05 Level of significance), so the hypothesis, 'There will be no significant influence of gender on social-cultural impact of the internet on the PG students of Gujarat has not been rejected in the present study.

Table-3 t-value

\begin{tabular}{|c|c|c|c|c|c|c|}
\hline Gender & $\mathbf{N}$ & Mean & SD & SE $_{\mathbf{D}}$ & M. Diff. & C. R. \\
\cline { 1 - 6 } Male & 100 & 126.9433 & 9.119777 & \multirow{2}{*}{0.739886} & 0.48 & 0.648749 \\
\cline { 1 - 5 } Female & 100 & 126.4633 & 9.003269 & & & \\
\hline
\end{tabular}

\section{Study-2 Influence of Academic stream on social-cultural impact}

F ratio 0.81 of Academic Stream was compared with F table value and it was found that observed F value is less than 6.76 at 0.01 level of significance. So the hypothesis, 'There will be no significant influence of academic stream on social-cultural impact of internet on the PG students of Gujarat State' has not been rejected in the present study.

\section{Study-3 Influence of frequency of internet access on social-cultural impact}

$\mathrm{F}$ ratio 2.94 for Influence of Internet Use was compared with $\mathrm{F}$ table value and found that observed value is less than 6.760 .01 level of significance. So the hypothesis, 'There will be no significant influence of frequency of internet access on social-cultural impact on the PG students of Gujarat State.' has not been rejected in the present study.

\section{Study-4 Interactive Influence of Gender and Academic Stream on social-cultural impact}

$\mathrm{F}$ ratio 0.90 was compared with $\mathrm{F}$ table value and it was found that observed $\mathrm{F}$ value is less than 6.76 at 0.01 level of significance. So the hypothesis, 'There will be no significant interactive influence between gender $\&$ academic stream on social-cultural impact of internet on the PG students of Gujarat State.' has not been rejected in the present study.

\section{Study-5 Interactive Influence of Gender and Internet Use on social-cultural impact}

$\mathrm{F}$ ratio 0.59 was compared with $\mathrm{F}$ table value and it was found that observed $\mathrm{F}$ value is less than 6.76 at 0.01 level of significance. So the hypothesis, 'There will be no significant interactive influence between gender $\&$ frequency of internet access on social-cultural impact of internet on the PG students of Gujarat State.' has not been rejected in the present study. 
Towards Excellence: An Indexed, Refereed \& Peer Reviewed Journal of Higher Education / Mr. A.J Bharvad \& Ms. Meenu Gupta / Page 1-9

\section{Study-6 Interactive Influence of Academic Stream and Internet Use on social-cultural impact}

$\mathrm{F}$ ratio 3.49 was compared with $\mathrm{F}$ table value and it was found that observed $\mathrm{F}$ value is less than 6.76 at 0.01 level of significance. So the hypothesis, 'There will be no significant interactive influence between academic stream \& frequency of internet access on socialcultural impact of internet on the PG students of Gujarat State.' has not been rejected in the present study.

Study-7 Interactive influence among Gender, Academic stream and Frequency of Internet Access on Socio-Cultural impact of the internet users

F ratio 4.69 was compared with $F$ table value and it was found that the observed $F$ value was more than 3.89 at 0.05 level of Significance. This reflects that there was a significant interactive influence between $\mathrm{A}^{*} \mathrm{~B} * \mathrm{C}$ on the Socio-Cultural impact of the Internet users. So the hypothesis, 'There will be no significant interactive influence among Gender, Academic Stream \& frequency of internet access on social-cultural impact of internet on the PG students of Gujarat State.' has been rejected in the present study.

To check which group has more impact than others, the $\mathrm{t}$ values and mean were calculated on all possible interactions. Out of which $t$ value of the only one pair showed significant difference between mean scores of Socio Culture Impact.

\section{Table-4 $t$-value for $A \times B \times C$}

\begin{tabular}{|l|r|r|r|r|r|r|r|r|r|r|r|}
\hline \multicolumn{10}{|c|}{ values for Int Use(A) X Gender(B) X Stream (C) } \\
\hline Group & & & & $\mathrm{A}_{1} \mathrm{~B}_{1} \mathrm{C}_{1}$ & $\mathrm{~A}_{2} \mathrm{~B}_{1} \mathrm{C}_{1}$ & $\mathrm{~A}_{1} \mathrm{~B}_{1} \mathrm{C}_{2}$ & $\mathrm{~A}_{2} \mathrm{~B}_{1} \mathrm{C}_{2}$ & $\mathrm{~A}_{1} \mathrm{~B}_{2} \mathrm{C}_{1}$ & $\mathrm{~A}_{2} \mathrm{~B}_{2} \mathrm{C}_{1}$ & $\mathrm{~A}_{1} \mathrm{~B}_{2} \mathrm{C}_{2}$ & $\mathrm{~A}_{2} \mathrm{~B}_{2} \mathrm{C}_{2}$ \\
\hline & $\mathrm{N}$ & & & 25 & 25 & 25 & 25 & 25 & 25 & 25 & 25 \\
\hline & & \multirow{2}{*}{ Mean } & & 126.8267 & 125.88 & 126.36 & 128.7067 & 126.0267 & 126.7467 & 125.0667 & 128.0133 \\
\hline & & & $\mathrm{SD}^{2}$ & 100.63 & 67.62 & 65.72 & 86.64 & 90.54 & 76.54 & 93.82 & 73.15 \\
\hline $\mathrm{A}_{2} \mathrm{~B}_{2} \mathrm{C}_{2}$ & 25 & 128.01 & 73.15 & 0.78 & 1.56 & 1.22 & 0.48 & 1.34 & 0.90 & 1.95 & 0.00 \\
\hline $\mathrm{A}_{1} \mathrm{~B}_{2} \mathrm{C}_{2}$ & 25 & 125.07 & 93.82 & 1.09 & 0.55 & 0.89 & $\underline{2.35}$ & 0.61 & 1.11 & 0.00 & \\
\hline $\mathrm{A}_{2} \mathrm{~B}_{2} \mathrm{C}_{1}$ & 25 & 126.75 & 76.54 & 0.05 & 0.63 & 0.28 & 1.33 & 0.48 & 0.00 & & \\
\hline $\mathrm{A}_{1} \mathrm{~B}_{2} \mathrm{C}_{1}$ & 25 & 126.03 & 90.54 & 0.50 & 0.10 & 0.23 & 1.74 & 0.00 & & & \\
\hline $\mathrm{A}_{2} \mathrm{~B}_{1} \mathrm{C}_{2}$ & 25 & 128.71 & 86.64 & 1.19 & 1.95 & 1.65 & 0.00 & & & & \\
\hline $\mathrm{A}_{1} \mathrm{~B}_{1} \mathrm{C}_{2}$ & 25 & 126.36 & 65.72 & 0.31 & 0.36 & 0.00 & & & & & \\
\hline $\mathrm{A}_{2} \mathrm{~B}_{1} \mathrm{C}_{1}$ & 25 & 125.88 & 67.62 & 0.63 & 0.00 & & & & & & \\
\hline $\mathrm{A}_{1} \mathrm{~B}_{1} \mathrm{C}_{1}$ & 25 & 126.83 & 100.63 & 0.00 & & & & & & & \\
\hline
\end{tabular}

\section{Interactive Group $\mathrm{A}_{1} \mathrm{~B}_{2} \mathrm{C}_{2}$ and $\mathrm{A}_{2} \mathrm{~B}_{1} \mathrm{C}_{2}$}

$\mathrm{t}_{\mathrm{cal}}$ of these group is 2.35, which is greater than 1.96 ( $\mathrm{t}_{\mathrm{tab}}$ at 0.05 Level of significance). The mean value of score of the group $\mathrm{A}_{2} \mathrm{~B}_{1} \mathrm{C}_{2}$ is greater than the mean value of the group $A_{1} B_{2} C_{2}$. So it was concluded that Excessive Male Other stream students 
Towards Excellence: An Indexed, Refereed \& Peer Reviewed Journal of Higher Education / Mr. A.J Bharvad \& Ms. Meenu Gupta / Page 1-9

$\left(\mathrm{A}_{2} \mathrm{~B}_{1} \mathrm{C}_{2}\right)$ have more socio cultural impact than Normal Female Other Stream students $\left(\mathrm{A}_{1}\right.$ $\mathrm{B}_{2} \mathrm{C}_{2}$ ) due to internet use.

\section{Findings}

Findings of the study were as following:

1. Male and Female Internet Users were found to have Socio-Cultural impact to the same extent.

2. The Science Stream and Other Stream Internet Users were found to have Socio-Cultural impact to the same extent.

3. The Normal Users and Excessive Internet Users were found to have Socio-Cultural impact to the same extent.

4. The Male and Female P.G. students of Science Stream and Other Stream Internet Users, were found to have Socio-Cultural impact to the same extent.

5. The Male and Female P.G. students of Normal Users and Excessive Internet Users students, were found to have Socio-Cultural impact to the same extent.

6. Science Stream and Other Stream Internet Users, Normal Users and Excessive Internet Users students were found to have Socio-Cultural impact to the same extent.

7. A significant interactive influence was found between Gender, Academic Stream and Internet Access on the Socio-Cultural impact of internet.

\section{Implication of the Study}

The following implications in the field of education are suggested:

- Teachers and researchers may address the problem of excessive use of internet and dependence in the young students.

- Young students must be made aware about the safe use of internet for education, information and other uses.

- Internet resources are equally important for the professional development and student's instruction by the teachers.

- The educational policy makers must restructure the curriculum with respect to necessity to connect to virtual world. 


\section{Conclusion}

Internet has become as important in our life as water and electricity. The culture change begins with the process of innovation and forming of new habits and the social change means that there occurs a change in course of activities of the people. The innovation of internet communication has led to wide spread changes in our life mainly in the manner of communicating with one another( emails and use of social media), day to day commercial activities( e- commerce activities), e-banking, e-education, school and college admission processes etc. The present study has also proved significant interactive influence between Gender, Academic Stream and Internet Access on the Socio-Cultural impact.

This research does not end here but is a projection to teachers and future researchers to study use of internet among the students and impact on marital status, employment, fertility, educational attainment, occupation and other variables. 


\section{REFERENCES:}

- Aggrawal J.C. (2007), Philosophical and Sociological Perceptive on Education, Delhi: Sharma Publications,

- Asthana,Bipin (2009) Measurements and Evaluation in Psychology \& Education. Agra: Agrawal Publication

- $\quad$ Best J.W., \& Kahn J.V. (2007), Research in Education (9 ${ }^{\text {th }}$ Edition), New Delhi: Prentice -Hall of India Pvt. Ltd.

- $\quad$ Mangal S. K. (2012), Essentials of Educational Psychology (6 ${ }^{\text {th }}$ Edition), New Delhi: PHI Learning Pvt. Ltd.

- Mathur S. S. (2013), A Sociological Approach to Indian Education: Agrawal Publications

- $\quad$ Shukla, S.S. (2007).Basics of Information Technology for Teachers. Varishen Prakashan, Ahmedabad.

Citations from Internet Sources:

- Wikepedia, The Free Encyclopaedia, Definition of Internet,

Retrieved Dec 17, 2015, from http:// en.wikipedia.org /wiki/internet

\section{Dr. A. J. Bharvad}

\&

\section{Ms. Meenu Gupta}

